scopy in their respective spheres, except that the non-biological institutions mentioned that especial emphrsis should be given to optical microscopy. The replies included eleven from sources outside the United States, but their requirements were almost identical with those from the industrial non-biological institutions, differing only in that 'skill in photography' was asked for in preference to 'knowledge of allied instruments'.

In almost all cases the duties expected of a trained electron microscopist were expected in a high order of perfection-not just to maintain the instrument, but to maintain it 'at its peak'- thus demanding a maximum of experience and training in the field and indicating a preference for postgraduate training.

Dr. Watson referred to the great shortage of research electron microscopists in the United States of America and stated that a strong plea could be made for graduate university courses in electron microscopy where men from diverse fields could be trained in the fundamentals of the subject and conduct electron microscopical research in their respective fields leading to postgraduate degrees.

S. WEINTroub

\title{
FREEZING FISH AT SEA
}

\begin{abstract}
A PRIMARY aim of the work at the Torry Research Station of the Department of Scientific and Industrial Research is the improvement in quality of fish as sold to the consumer. Particular attention has been paid to the problem of fish, principally cod, caught in Arctic waters, since the earlier part of the catch may be some twelve days old when it is landed. During the voyage the fish are stowed in holds in crushed ice, and it is obvious that the quality at landing could be markedly improved if the fish were quick-frozen soon after catching. "Report on an Experiment into the Freezing of Fish at Sea" (pp. 65+6 plates. London : White Fish Authority, 1957. 5s.) is a record of an extensive and impressive large-scale experiment to examine the practical feasibility of such a scheme of quick-freezing at sea. The technical developments were undertaken by the Department of Scientific and Industrial Research, and in the field work the White Fish Authority and the trawler owners gave full co-operation.
\end{abstract}

Five main phases of the technical work are fully described : (1) the experimental development in the Torry engineering laboratories of a suitable type of freezer for whole cod; (2) the sez-trials of a prototype freezer in the Station's motor fishing vessel;
(3) collection and analysis of operational data on fourteen typical trawler trips to northern waters, to provide a design basis for a full-scale plant; (4) the construction and shore testing of the fullscale freezing plant and the conversion of a typical trawler, Northern Wave, to take the installation; (5) the results of the eight experimental voyages with the freezing plant in action.

The freezing plant has a capacity of about 8 tons of fish per day and roughly 23 per cent of all fish eaught was quick-frozen. Freezing was effected by directcontact plates through which refrigerant at $-40^{\circ} \mathrm{F}$. was circulated, and the frozen blocks were stored at $-20^{\circ} \mathrm{F}$. in a specially installed cold store.

Details are given of the marketing experience and reaction to the product, and the financial and economic implications are summarized. The scale of the experiment was not large enough to permit of firm conclusions on all these points, but the findings should be of marked assistance to trawler owners contemplating the adoption of freezing at sea. The outstanding feature of the experiment was the successful performance of the freezing equipment under all weather conditions, and the technical feasibility of the project was amply demonstrated.

\section{CARTOGRAPHY}

THE first volume of the official records of the first United Nations Regional Cartographic Conference for Asia and the Far East consisted of the report of the Conference. This has now been supplemented by a second volume*. Of this, the first 22 pages, or about one-sixth, consists of summary records of the discussions, which took as their starting point a recognition that "accurate maps are a prerequisite to the proper development of the world resources which in many cases lie in relatively unexplored regions", and that topographical mapping must necessarily precede geological or other specialized surveys. Delegates were concerned largely with the need of the less-developed countries for technicel assistance in both survey and map compilation; and with the means by which publication of further sheets of the International Map of the World on the Millionth Scale might be encouraged. The

* United Nations Regional Cartographic Conference for Asia and the Far East, 15-25 February, 1955, Mussoorie, India. Vol. 2: Proceedings of the Conference and Technical Papers. Pp. $x+133+2$ maps. (New York : United Nations; London: H.M. Stationery Office,
"Tөchnical Papers" follow and vary from an account of the status of publication of the International Map accompanied by communications on its future from various interested parties to descriptions of some of the most recent developments in survey methods.

The report on the "International Map of the World on the Millionth Scale"* is, except to the cartographically well informed, a most misleading document. It misleads particularly by its index map, which conveys the impression that the Map itself is well on the way to completion. This is far from being the case, and since it is important that scientists generally should be aware of the realities of the situation regarding this basic map of the world, it is well to recall the history of this project.

The original proposal for an international map of the world on a scale of $1: 1$ million (about 16 miles to 1 in.) was made by Prof. A. Penck at the Internationsl Geographical Congress in Berne in 1891. It

* International Map of the World on the Millionth Scale : Report for 1955 prepared by the Secretariat. Pp. Hii $+84+1$ map. (New York: United Nations; London: H.
0.80 dollars ; 58. $6 d . ; 3.50$ Swiss francs. 